\title{
Concessão florestal na Amazônia brasileira
}

\author{
Forest concessions in the brazilian Amazon
}

\author{
Maisa Isabela Rodrigues ${ }^{\mathrm{I}}$,Álvaro Nogueira de Souza ${ }^{\mathrm{II}}$, \\ Maísa Santos Joaquim ${ }^{\mathrm{II}}$, Ilvan Medeiros Lustosa Júnior ${ }^{\mathrm{IV}}$, \\ Reginaldo Sérgio Pereira ${ }^{\mathrm{II}}$
}

\begin{abstract}
Resumo
O manejo florestal é uma boa alternativa à exploração predatória dos recursos florestais. Para aumentar a adoção do manejo florestal e evitar o desmatamento ilegal e a ocupação desordenada das florestas públicas, o Governo instituiu a política de concessão florestal. O estudo teve por objetivo descrever a trajetória da política de concessão florestal no Brasil, abordando seus avanços, bem como os aspectos positivos e negativos da modalidade de gestão de florestas públicas supracitada. O trabalho foi realizado por meio de revisão bibliográfica sobre o manejo florestal, com destaque para as concessões florestais no Brasil. Atualmente, o Brasil possui 6 (seis) FLONAs sob concessão, sendo 4 (quatro) delas no estado do Pará, e 2 (duas) em Rondônia. Até o momento, as concessões florestais não atenderam às expectativas iniciais. Como pontos positivos, pode-se observar a redução da vulnerabilidade das florestas sob concessão e a geração de empregos diretos, beneficiando a população local. A destinação de áreas para a concessão ficou abaixo do planejado pelo governo. No entanto, apesar da lenta implantação, espera-se que haja uma rápida expansão devido às lições adquiridas com os primeiros contratos. Assim, acredita-se que o processo de concessão florestal brasileiro está amadurecendo de forma lenta, mas gradual. As atividades de monitoramento e fiscalização são consideradas elementos frágeis das concessões florestais, sendo necessárias ações que garantam a sustentabilidade das florestas. A redução da exploração ilegal é um desafio para o governo. Assim, caso o mercado seja abarrotado de madeira advinda da exploração ilegal, o esforço realizado para implantar a política de concessão florestal poderá ter sido em vão. Por fim, as concessões florestais são recentes no Brasil, mas estão evoluindo a cada ano, tanto em quantidade de áreas destinadas quanto de produtividade de madeira. Nesse contexto, pesquisas se fazem necessárias para um maior conhecimento dos resultados apresentados pela gestão.
\end{abstract}

Palavras-chave: Floresta Amazônica; Política florestal; Manejo florestal sustentável

\footnotetext{
Engenheira Florestal, Dra., Pesquisadora Autônoma, Departamento de Engenharia Florestal, Universidade de Brasília, Campus Universitário Darcy Ribeiro, Caixa Postal 04357, CEP 70910-900, Asa Norte, Brasília (DF), Brasil. maisarodrigues.eng@gmail.com (ORCID: 0000-0003-2654-8245) Engenheiro Florestal, Dr., Professor do Departamento de Engenharia Florestal, Universidade de Brasília, Campus Universitário Darcy Ribeiro, Caixa Postal 04357, CEP 70910-900, Asa Norte, Brasília (DF), Brasil. ansouza@unb.br (ORCID: 0000-0002-6869-2715) / reginaldosp@unb.br (ORCID: 0000-0002-6614-6825)

III Engenheira Florestal, Dra., Professora do Instituto Federal de Brasília, Professora da Faculdade de Agronomia e Medicina Veterinária, Universidade de Brasília, Campus Universitário Darcy Ribeiro, Caixa Postal 04357, CEP 70910-900, Asa Norte, Brasília (DF), Brasil. maisajoaquim@unb.br (ORCID: 0000-0002-2867-0941)

Iv Engenheiro Florestal, Dr., Professor do Instituto Federal de Brasília, Campus Planaltina, CEP 73380-900, Planaltina (DF), Brasil. ilvan.junior@ifb. edu.br (ORCID: 0000-0002-3873-737X)
} 


\begin{abstract}
The forest management is a good alternative over predatory exploitation of the forestry resources. To increase the forest management acceptance, avoid the illegal deforestation and the disordered occupation of public forests, the Government has implemented the forest concession policy. The work was performed by a literature review on the forest management, highlighting the forest concessions in Brazil. Currently, Brazil has 6 (six) forest areas under concession, 4 (four) of them in Pará state, and 2 (two) in Rondônia state. So far, the forest concessions did not attend the initial expectations. As good aspects, it is observed the reduction of vulnerability in forests under concessions and the creation of direct jobs, benefiting the local population. The destination of areas for concession was below the governmental expectations. However, despite the slow implementation, it is expected a quick expansion due the lessons learned with the firsts contracts. Therefore, it is believed that the Brazilian forest concession process is maturing gradually, although in a slow way. The monitoring and supervision activities are considered fragile elements of the forest concession, proving necessary actions to ensure the sustainability of forests. The reduction of the illegal exploitation remains a challenge for the government. If the market is supplied with wood from illegal exploitation, the effort to implement forest concessions policies might have been in vain. Finally, forest concessions are recent in Brazil, but they are evolving each year, both in number of the designated areas and in wood productivity. In this context, researchesare necessary for a greater knowledge of the results presented by the management.
\end{abstract}

Keywords: Brazilian Amazon; Forestry policy; Sustainable forest management

\title{
Introdução
}

Ao analisar o comportamento do mercado internacional de madeiras tropicais, Silva, Silva e Cordeiro (2012) apontaram que o declínio da produção de madeira tropical pela Indonésia e Malásia foi devido à diminuição das áreas passíveis de exploração florestal. Esses países são os principais fornecedores de madeira tropical, e, de acordo com Higuchi et al. (2006), deixarão de fornecê-la em 2020.

Considerando a expectativa de redução da oferta de madeira tropical pelos países asiáticos e pela bacia do Congo, o Brasil assume posição de destaque no fornecimento dessa matériaprima. Dessa forma, o país deve se preparar de forma técnica e administrativa para atender à futura demanda externa, e também às demandas internas atuais (INSTITUTO FLORESTA TROPICAL, 2014). A tendência verificada nesse setor apresenta característica de nomadismo, em que, havendo o esgotamento das reservas florestais dos países asiáticos, ocorrerá o aumento da pressão sobre as florestas nacionais, uma vez que a floresta Amazônica é a última fronteira florestal (HIGUCHI et al., 2010).

O manejo florestal é considerado uma boa alternativa para garantir a continuidade da produção de madeira, não sendo necessária a alteração de uso de solo nas áreas manejadas (ÂAGELO et al., 2014). Segundo esses autores, além dos benefícios ambientais, as práticas de manejo florestal proporcionam melhorias na qualidade de vida da população local, por meio da geração de emprego e renda, sendo um incentivo para a economia formal. Para Silva et al. (2009), o manejo florestal é reconhecido em todo o mundo como mecanismo capaz de manter a floresta de forma sustentável. Entretanto, esses autores argumentam que, para a real efetivação do manejo, deve haver ações de fiscalização e monitoramento, além de difusão de conhecimento e incentivos advindos da sociedade.

A atividade madeireira na Amazônia brasileira é extremamente predatória (SILVA; SILVA; CORDEIRO, 2012). Como forma de aumentar a adoção das técnicas de manejo florestal sustentável, foi instituída a política de concessão florestal, implementada pelo Governo Federal, por meio da Lei n.o 11.284/2006 (BRASIL, 2006). Além de garantir a oferta contínua de produtos florestais madeireiros e não madeireiros, a concessão florestal também objetiva desacelerar a ocupação desordenada e a exploração ilegal das florestas. Assim, é possível manejar florestas públicas, podendo retirar dela produtos madeireiros e não madeireiros, em que os concessionários 
pagam à União valores definidos no processo de licitação pública das áreas a serem manejadas.

Por definição, a concessão florestal consiste na delegação onerosa do direito de praticar o manejo florestal sustentável em uma unidade de conservação, objetivando a exploração de produtos e serviços da floresta (BRASIL, 2006). Assim, a concessão florestal pode ser entendida como um instrumento econômico que visa ao uso sustentável das florestas.

Esperava-se que 13 milhões de hectares de florestas fossem disponibilizados para concessão até 2018 (BRASIL, 2009b). No entanto, após 8 anos da assinatura do primeiro contrato de concessão, apenas 13,48\% das áreas estimadas foram concedidas. Para Azevedo Ramos, Silva e Merry (2015), as concessões florestais são complexas, e de difícil implantação e, apesar de apresentarem falhas, o modelo de concessões florestais brasileiro está amadurecendo de forma lenta, mas constante.

Diante do exposto, este estudo teve por objetivo fazer uma descrição da aplicação da política de concessão florestal no Brasil, em que se levou em consideração os aspectos positivos e negativos da modalidade de gestão de florestas públicas. Objetivou-se também apontar os avanços observados após 10 anos da aprovação da Lei de gestão de florestas públicas (Lei n.․ㅜ 11.284/2006), e oito anos após a assinatura do primeiro contrato de concessão florestal (BRASIL, 2006).

\section{Material e métodos}

O presente trabalho foi realizado por meio de uma revisão bibliográfica sobre o manejo florestal sustentável na Amazônia brasileira, com enfoque nas concessões de Florestas Nacionais, Unidades de Conservação de uso sustentável. Para isso, foram realizadas pesquisas acerca do tema em periódicos, em sites oficiais do governo e também na legislação brasileira que regulamenta as atividades de manejo florestal.

\section{Unidades de conservação}

De acordo com a Constituição Federal de 1988 (BRASIL, 1988), todos têm direito ao meio ambiente equilibrado, sendo de responsabilidade do Poder Público e da coletividade a preservação, para as presentes e futuras gerações. Visando ao cumprimento do direito supracitado, as unidades de conservação são instrumentos destinados a garantir a preservação dos recursos em questão. Tem-se por definição de unidade de conservação o espaço territorial e seus recursos, com características naturais relevantes e limites definidos (BRASIL, 2000). Essas áreas são instituídas pelo Poder Público, e possuem um regime de administração que deve garantir a sua proteção (BRASIL, 2000).

Até o ano 2000, não havia no Brasil um estatuto acerca das unidades de conservação. A legislação vigente era desintegrada, havendo o Código Florestal Brasileiro (Lei n.o 4.771/1965) e diversas outras leis, além de decretos e atos administrativos normativos do Instituto Brasileiro do Meio Ambiente e dos Recursos Naturais Renováveis (IBAMA) e Conselho Nacional do Meio Ambiente (CONAMA) (SANTOS, 2008). Como forma de gerar um estatuto para gerir as unidades de conservação, foi elaborado o Sistema Nacional de Unidades de Conservação (SNUC), instituído pela Lei n. ${ }^{9}$ 9.985/2000, com o objetivo de estabelecer critérios e normas para a criação, implantação e gestão das unidades de conservação. O SNUC promoveu melhorias no processo de criação, implantação e gestão das unidades de conservação, além de estabelecer ferramentas que permitiram a participação da sociedade na gestão, potencializando assim a relação entre os cidadãos, o Estado e o meio ambiente (MEDEIROS; ARAÚJO, 2011).

O SNUC possui 12 categorias de unidades de conservação, as quais dividem-se em dois grupos, ou seja, cinco são classificadas no grupo das unidades de conservação de proteção integral (Estação Ecológica, Reserva Biológica, Parque Nacional, Monumento Natural e Refúgio 
da Vida Silvestre) e sete no grupo das unidades de uso sustentável (Área de Proteção Ambiental, Área de Relevante Interesse Ecológico, Floresta Nacional, Reserva Extrativista, Reserva de Fauna, Reserva de Desenvolvimento Sustentável e Reserva Particular do Patrimônio Nacional) (BRASIL, 2000)

Existem no Brasil 2.376 unidades de conservação que estão em acordo com o SNUC, totalizando uma área de $2.549 .330 \mathrm{~km}^{2}$, nas esferas federal, estadual e municipal. Destas, 761 são de proteção integral $\left(663.083 \mathrm{~km}^{2}\right)$ e 1.615 de uso sustentável $\left(1.886 .247 \mathrm{~km}^{2}\right)$ (BRASIL, 2019). O Instituto Chico Mendes de Biodiversidade (ICMBio) é o órgão competente responsável pela gestão das unidades de conservação federais. No âmbito estadual e municipal, a atividade em questão é atribuída aos órgãos estaduais e municipais, respectivamente.

Quanto às Florestas Nacionais (FLONAs), essas são caracterizadas como áreas com cobertura vegetal predominantemente nativa, e têm por objetivo o uso sustentável dos recursos, bem como a pesquisa científica, dando ênfase na exploração sustentável de florestas nativas (BRASIL, 2000). Essa modalidade de unidade de conservação está presente em diversos outros países, como Canadá, Estados Unidos, Chile, Venezuela, entre outros, havendo uma gama de formas de gerenciamento. No Brasil, elas somam 108 unidades de conservação, com área de aproximadamente $314.023 \mathrm{Km}^{2}$ (BRASIL, 2019). O governo criou o Programa Florestas Nacionais em 1998, com o objetivo de implementar o manejo sustentável e promover a criação de novas áreas, de modo a desenvolver de forma sustentável a exploração de madeira e atender à demanda prevista (GODOY, 2006).

\section{Manejo florestal na Amazônia brasileira}

A floresta Amazônica é considerada patrimônio nacional, e a sua utilização deverá ser feita de forma que seja assegurada a preservação ambiental, inclusive no que se refere aos recursos naturais (BRASIL, 1988). Visto que há uma demanda por produtos florestais madeireiros e não madeireiros, as práticas de manejo florestal sustentável são consideradas as mais adequadas para que essa demanda seja garantida e, ao mesmo tempo, evitar a degradação ambiental das florestas. No manejo florestal, deve-se manter o capital inicial da floresta, sendo explorado apenas seus juros, de forma que seja mantido o potencial de crescimento, retirando-se apenas o seu incremento, em ciclos periódicos (CARVALHO et al., 1984).

O termo 'Manejo Florestal Sustentável' surgiu em meados da década de 1950, quando foram realizados os primeiros inventários florestais na Amazônia (HIGUCHI et al., 2010). Segundo a Lei n. 11.284/2006 (BRASIL, 2006), o manejo florestal sustentável consiste na administração da floresta para a obtenção de benefícios econômicos, sociais e ambientais, considerando-se a utilização de produtos florestais madeireiros e não madeireiros, assim como bens e serviços da floresta. Dessa forma, é possível atender à demanda por produtos florestais madeireiros e não madeireiros e, ao mesmo tempo, reduzir os danos causados aos espécimes remanescentes, e garantir a perpetuidade dos recursos naturais.

O manejo florestal para a exploração de produtos florestais madeireiros e não madeireiros na Amazônia está previsto por lei desde 1965, por meio do Código Florestal Brasileiro (BRASIL, 1965). No entanto, sua regulamentação foi feita após 30 anos, pelo Decreto $n^{\circ} 1.282 / 1995$. Antes da efetiva implantação do manejo florestal sustentável, a retirada de árvores da Amazônia brasileira era feita por exploração convencional e predatória, não havendo preocupações com os indivíduos remanescentes ou com a regeneração da floresta.

Até meados da década de 1980, a atividade madeireira consistia em uma atividade secundária, sendo a madeira apenas um subproduto da execução de projetos agropecuários (HIGUCHI et al., 2010). Dessa forma, o manejo florestal sustentável tornou-se uma alternativa ao modelo de exploração convencional e predatória, tendo por objetivo principal minimizar o impacto ambiental oriundo da exploração convencional.

A madeira legal de origem amazônica provém de planos de manejo florestal sustentável 
(PMFS), ou de Autorização de Desmatamento, pois é permitida a retirada de até $20 \%$ da cobertura vegetal nativa do bioma em questão para a alteração do uso do solo (BRASIL, 2012). O PMFS consiste em um documento técnico necessário para a implantação das atividades de manejo florestal, sendo, para as FLONAs, o IBAMA o órgão competente responsável pela aprovação do PMFS e posterior fiscalização das atividades a serem realizadas.

O manejo florestal é classificado de acordo com o método como as toras são retiradas da floresta. O manejo que utiliza máquinas de arraste das toras possui intensidade máxima de corte equivalente a $30 \mathrm{~m}^{3} \cdot \mathrm{ha}^{-1}$, com ciclo inicial de 35 anos. Já o manejo que não utiliza máquinas para o arraste das toras apresenta intensidade máxima de corte correspondente a $10 \mathrm{~m}^{3} \cdot \mathrm{ha}^{-1}$, e ciclo inicial mínimo de 10 anos. Para ambas as categorias, deve-se considerar o diâmetro mínimo de corte de $50 \mathrm{~cm}$, e incremento anual de $0,86 \mathrm{~m}^{3} \cdot$ ha $^{-1}$ quando não há estudos específicos para a área a ser manejada (BRASIL, 2009b). Para Ruschel (2008), os ciclos de corte preestabelecidos são baseados em conhecimentos teóricos, que na prática precisam de comprovação.

Existe uma série de experimentos realizados na Amazônia que apresentam vantagens da exploração florestal manejada ao se comparar com as práticas de exploração convencional. Pereira et al. (2010) observaram os seguintes benefícios da exploração manejada: é mantido o valor futuro da floresta; há redução de $12 \%$ dos custos da madeira; os impactos causados sobre o solo e as árvores remanescentes são reduzidos em 50\%; o desperdício da madeira corresponde a apenas um terço do desperdício causado pela exploração convencional; e há redução de $36 \%$ da emissão de carbono. Como pontos fracos do manejo florestal, destacam-se aspectos de cunho governamental, como a burocracia do processo, falhas na fiscalização, problemas de falta de crédito compatível para a atividade, entre outros (ÂNGELO et al., 2014).

A carência de informações acerca da viabilidade financeira consiste em um dos principais entraves que afetam a adoção das práticas de manejo florestal (SABOGAL et al., 2006). Duas das principais pesquisas sobre manejo florestal na Amazônia brasileira, em Manaus (INPA) e na FLONA Tapajós (EMBRAPA-CPATU), foram realizadas em escala experimental, não sendo desenvolvidos estudos econômicos, o que consiste em uma lacuna das pesquisas em questão (HIGUCHI et al., 2010).

Necessita-se também de avanço das pesquisas para embasar não apenas a produção volumétrica, mas também a normatização, tendo por base a ecologia das espécies e contemplando as particularidades ambientais da floresta (SILVA; SILVA; CORDEIRO, 2012). Há possibilidade de melhorias através de disseminação de informações, capacitação da mão de obra em todos os níveis, monitoramento das atividades, pressão ao uso ilegal das florestas e diminuição da burocracia (SILVA et al., 2009).

\section{Concessão florestal}

A concessão florestal é uma modalidade de gestão de florestas públicas adotada por diversos países, como Estados Unidos, Malásia e Indonésia (JUVENAL; MATTOS, 2002). As mais antigas concessões florestais foram registradas na África Central e Oriental, datadas do século XIX (DRIGO, 2010). Para Vilanova et al. (2012), as concessões florestais representam parte importante da silvicultura em países tropicais. O modelo de gestão de florestas públicas foi implantado há mais de 20 anos na América Latina. Na Venezuela, as primeiras concessões foram implantadas na década de 1970, na Bolívia, desde 1996, e no Peru, desde 2001 (KARSENTY et al., 2008; DRIGO, 2010; VILANOVA et al., 2012).

Segundo Carneiro, Amaral Neto e Castro (2013), o Brasil tentou implantar as concessões florestais em três ocasiões: na década de 1970, durante a ditadura militar, e nos governos de Fernando Henrique Cardoso e Luiz Inácio Lula da Silva. Na segunda tentativa, a proposta foi duramente criticada devido à suspeita de privatização das floretas nacionais. No governo de Luiz Inácio Lula da Silva, em 2005, a proposta de reformulação da Lei ${ }^{\circ} 4.776 / 2005$ foi contestada, pois se temia que as florestas nacionais fossem entregues a empresas estrangeiras. Assim, segundo 
o mesmo autor, o governo criou em 2006 a lei de gestão de florestas públicas (Lei no 11.284/2006) como forma de minimizar os temores e críticas ao sistema, complementando o projeto existente. A Lei n. ${ }^{\circ}$ 11.284/2006, regulamentada pelo Decreto $n^{\circ} 6.063 / 2007$, instituiu o Serviço Florestal Brasileiro (SFB), órgão gestor responsável pelo processo de concessão florestal, e trata da gestão de florestas públicas para a produção sustentável.

Objetivando o uso sustentável dos recursos florestais, a Lei n.ำ 11.284/2006 apresenta três modalidades de gestão de florestas públicas: a destinação de florestas públicas para as comunidades tradicionais, a gestão direta, em que o estado realiza o manejo florestal, e a concessão florestal. De acordo com a nº Lei 11.284/2006, a concessão pode ser feita para a exploração de florestas públicas, naturais ou plantadas, podendo ser explorados recursos florestais madeireiros e não madeireiros, além de serviços de turismo. A legislação permite que os governos estaduais, municipais e federal gerenciem seus recursos florestais. Vale ressaltar que não é permitida a exploração de recursos genéticos, minerais e hidrográficos, além de animais e créditos de carbono (AZEVEDO RAMOS; SILVA; MERRY, 2015).

A política de concessões florestais não visa apenas atender à demanda por produtos e serviços da floresta, por meio do uso sustentável. A premissa defendida pelo documento é de que a concessão florestal poderá dificultar o desmatamento, a grilagem de terras públicas e a ocupação desordenada da floresta, e, simultaneamente, propiciar uma gestão sustentável destas, aumentando a renda e melhorando a qualidade de vida da população local (GODOY, 2006; SILVA et al., 2009). A legislação em questão visa também implantar o manejo florestal sustentável em florestas públicas.

O direito de manejar florestas públicas pode ser dado, pelo governo, a empresas brasileiras e a comunidades, necessariamente, pessoas jurídicas. A Lei de gestão de florestas públicas estabeleceu como prioridade para as concessões as comunidades que já habitam as FLONAS, ou sobre a qual estas possuem direito de uso, sendo que o foco da Lei é definir sob quais condições as empresas de capital nacional ou misto poderiam acessar os estoques florestais (CARNEIRO; AMARAL NETO; CASTRO, 2013). A empresa que adquire a concessão terá o direito de manejar a área por um período de 40 anos. Ao final do contrato de concessão, a empresa concessionária deverá devolver a unidade de manejo de acordo com as condições previstas no edital da concessão (BRASIL, 2006). Ao conceder terras públicas para serem manejadas, ocorre a delegação de direitos e deveres, do poder público para o privado (BRASIL, 2006). No entanto, a concessão florestal não dá ao concessionário qualquer direito de posse pela área, ela permite apenas a realização das atividades descritas no contrato.

Dentre as terras públicas (áreas militares, terras indígenas e unidades de conservação), apenas as unidades de conservação de uso sustentável que possuem plano de manejo e foram inscritas no Cadastro Anual de Florestas Públicas e incluídas no Plano Anual de Outorga Florestal (PAOF) são passíveis de concessão florestal. Salienta-se que o modelo de gestão em questão não pode ser aplicado às Reservas de Desenvolvimento Sustentável (RDS) e Reservas Extrativistas (RESEX), pois são unidades de conservação de uso sustentável destinadas ao uso comunitário (SERVIÇO FLORESTAL BRASILEIRO, 2019).

Dos 240 milhões de hectares de Florestas Públicas Federais, apenas 1.051.669,95 hectares foram concedidos para concessões florestais, e 3.803.313,32 hectares (1,23 \%) estão aptos à implantação de concessões florestais (SERVIÇO FLORESTAL BRASILEIRO, 2019). Como áreas que não estão aptas para concessão, estão as unidades de conservação que já se encontram sob concessão, as unidades de conservação que não apresentam plano de manejo, e as demais terras públicas que não são passíveis de concessão florestal. O potencial de produção de madeira em toras por florestas públicas passíveis de concessão em 2016 está entre 978 mil e 1,5 milhão de $\mathrm{m}^{3}$ (SERVIÇO FLORESTAL BRASILEIRO, 2019), o que representa aproximadamente $10 \%$ da madeira em tora produzida pela Amazônia Legal em 2018.

Até meados de 2019, constavam 17 contratos de concessão florestal. As FLONAs destinadas à concessão estão nos estados do Pará e Rondônia (Tabela 1). Destas, apenas 3 (três) 
Unidades de Manejo Florestal (UMF) não estão em produção, sendo as 2 (duas) UMFs da FLONA Crepori, e a UMF II da FLONA Caxiuanã. Os contratos de concessão florestal da FLONA Crepori encontram-se suspensos judicialmente. Já o contrato de concessão florestal da UMF II da FLONA Jamari foi rescindido em 2012, após apenas um ano de exploração madeireira.

\section{Tabela 1 - Resumo das concessões florestais no Brasil}

Table 1 - Summary of forest concessions in Brazil

\begin{tabular}{|c|c|c|c|c|c|}
\hline \multirow{2}{*}{$\begin{array}{c}\text { FLONAs } \\
\text { sob Concessão }\end{array}$} & \multicolumn{5}{|c|}{ Área das UMFs (ha) } \\
\hline & UMF I & UMF II & UMF III & UMF IV & UMF V \\
\hline Jamari - RO & $17.176,36$ & $32.998,10^{2}$ & $46.184,20$ & - & - \\
\hline Saracá-Taquera - PA & - & $22.769,82$ & $18.933,62$ & - & - \\
\hline Jacundá - RO & $55.014,27$ & $32.757,96$ & - & - & - \\
\hline Saracá-Taquera - PA (Lote sul) & $26.898,00$ & $59.408,00$ & - & - & - \\
\hline Crepori - PA & & $134.148,31^{1}$ & $59.863,90^{1}$ & - & - \\
\hline Altamira - PA & $39.073,00$ & $112.994,00$ & $98.414,00$ & $111.436,00$ & - \\
\hline Caxiuanã - PA & $37.365,15$ & $87.067,18^{1}$ & $52.168,08$ & & \\
\hline Total & \multicolumn{5}{|c|}{$1.051 .669,95$} \\
\hline FLONAs & \multicolumn{5}{|c|}{ Área das UMFs (ha) } \\
\hline em Processo de Concessão & UMF I & UMF II & UMF III & UMF IV & UMF V \\
\hline Crepori - PA (Lote 2) & $39.353,90$ & - & - & $209.360,20$ & - \\
\hline Itaituba (I e II) - PA & $39.037,41$ & $126.735,38$ & $129.277,81$ & - & - \\
\hline Amapá - AP & $150.981,29$ & $35.257,65$ & $80.422,60$ & - & - \\
\hline Amana - PA & $30.798,00$ & $19.029,00$ & $29.207,00$ & $42.077,00$ & $89.049,00$ \\
\hline Amana - (PA) (Lote 2) & $29.886,86$ & $133.240,65$ & $140.126,40$ & & \\
\hline Total & \multicolumn{5}{|c|}{$1.323 .840,15$} \\
\hline
\end{tabular}

Fonte: Serviço Florestal Brasileiro (2019) - adaptado

Em que: $\left(^{1}\right)$ UMF sem produção e $\left(^{2}\right)$ rescisão do contrato de concessão florestal.

A produção de madeira nas concessões florestais representa aproximadamente $1,5 \%$ da produção de madeira nativa em toras no ano de 2017. Após 8 (oito) anos, foram produzidos aproximadamente $897 \mathrm{mil} \mathrm{m}^{3}$ de madeira pelas concessões florestais (SERVIÇO FLORESTAL BRASILEIRO, 2019). É observada uma baixa produtividade inicial das áreas. No entanto, a produtividade alcançada nas UMFs está apresentando valores mais satisfatórios com o passar do tempo. Apesar da lenta implantação das concessões florestais na Amazônia, espera-se que haja uma rápida expansão, devido às lições adquiridas nos primeiros contratos (INSTITUTO FLORESTA TROPICAL, 2014).

Para o ano de 2020, o PAOF apresenta 14 (quatorze) novas áreas para a implantação de concessão florestal no bioma Amazônico. Essas áreas estão localizadas nos estados do Amazonas, Pará, Amapá, Roraima e Rondônia e apresentam potencial de produção anual entre 1,4 milhões de $\mathrm{m}^{3}$ e 2,1 milhões de $\mathrm{m}^{3}$ (SERVIÇO FLORESTAL BRASILEIRO, 2019).

As concessões florestais não atenderam às expectativas iniciais, de modo que a destinação de áreas para a concessão florestal ficou muito aquém do esperado. Esperava-se que 13 milhões de hectares de florestas fossem disponibilizados para concessão até 2018 (BRASIL, 2009a). No entanto, em 2019 , apenas $8 \%$ da área esperada foi destinada.

As Florestas Nacionais têm por objetivo o uso múltiplo e sustentável dos recursos, e essa meta não foi atingida pelas concessões, pois apenas a madeira está sendo explorada (FERNANDES 
et al., 2017). Além de ser um dos critérios de bonificação previstos no contrato de concessão florestal, a comercialização de produtos florestais não madeireiros consiste em mais uma fonte de receita do investimento em concessão florestal. As estimativas, tanto quantitativas quanto a periodicidade, de produtos florestais não madeireiros (castanhas, óleo-resina, sementes, etc.) com valor comercial deveriam constar no inventário florestal (NOGUEIRA; RODRIGUES, 2007), uma vez que podem agregar valor ao investimento.

Como ponto positivo, pode-se observar uma menor vulnerabilidade das FLONAs sob concessão, uma vez que as empresas concessionárias são as principais interessadas em resguardar as áreas supracitadas. Apesar da existência de invasões em UC para o roubo de madeira, menos de $6 \%$ são em áreas de concessão florestal, indicativo de que o modelo de gestão tem inibido a extração ilegal de madeira (MUNIZ; PINHEIRO, 2019). No período de 2012 a 2015, a FLONA Altamira apresentou redução das taxas de desmatamento e, dentre os fatores que podem explicar a redução do desmatamento na UC, está o fato de que aproximadamente $50 \%$ da FLONA está sob concessão florestal (ARAÚJO et al., 2017). Nesse contexto, as concessões florestais estão cumprindo a missão de resguardar as terras públicas no que se refere à exploração ilegal de seus recursos naturais.

Outro benefício das concessões florestais é a geração de empregos diretos, promovendo, assim, melhorias sociais e econômicas para a população local. Por outro lado, Silva et al. (2009) relataram que as atividades de monitoramento e fiscalização podem ser os elementos mais frágeis das concessões florestais, fazendo-se necessárias ações para que a sustentabilidade das florestas não seja comprometida.

Analisando o estado do Pará no período de 2011 e 2012, concluiu-se que 78\% da exploração madeireira foi produzida em áreas não autorizadas, e ao analisar os PMFS autorizados, constatouse que somente $4 \%$ apresentavam indicativos de exploração madeireira de boa qualidade (CENTRO DE ESTUDOS EM SUSTENTABILIDADE, 2016). Para garantir que o programa de concessões florestais tenha bons resultados, deve-se investir no combate à extração ilegal de madeira (LIMA et al., 2018). Todo o esforço realizado para a implantação da política de concessão florestal poderá ser inútil se o mercado de madeiras tropicais continuar sendo inundado com produtos mais baratos, gerados a partir de uma produção ilegal (AZEVEDO RAMOS; SILVA; MERRY, 2015), uma vez que o produto advindo de áreas de manejo florestal sustentável não consegue competir por preço com o produto que apresenta origem ilícita.

\section{Considerações finais}

As concessões florestais representam um avanço no que se refere à gestão de florestas públicas no Brasil. Por meio delas, pode-se promover o uso sustentável das florestas, o aumento da oferta de madeira, e melhorias sociais e econômicas, através da geração de empregos para a população local. Além disso, a política em questão também exerce função de proteção das florestas, pois impede o avanço da ocupação desordenada e grilagem de terras, práticas comuns na região norte do país.

As concessões florestais não foram tão abrangentes como se esperava. Mas, apesar de pouco expressiva, a produção de madeira pelas concessões florestais evolui a cada ano. No entanto, para consolidar a política de concessões, deve-se combater a entrada de madeira ilegal no mercado, uma vez que a madeira de manejo florestal não consegue competir por preço com o produto ilegal.

A concessão florestal no Brasil é muito recente. Dessa forma, necessita-se pesquisas sobre o tema, tanto no que se refere às questões técnicas inerentes ao manejo florestal sustentável, quanto a questões de viabilidade financeira da concessão florestal. A realização de pesquisas no setor poderá proporcionar maior nível de entendimento acerca dos resultados apresentados pela modalidade de gestão, além de servir como base para ajustes na política. 


\section{Referências}

ÂNGELO, H. et al. Análise estratégica do manejo florestal na Amazônia brasileira. Floresta, Curitiba, v. 44, n. 3, p. 341-348, 2014.

ARAÚJO, E. et al. Unidades de conservação mais desmatadas da Amazônia Legal (2012-2015). Belém: Imazon, 2017. 94 p. Disponível em: https://imazon.org.br/PDFimazon/Portugues/livros/ UCS mais desmatadas Amazonia_2012-2015.pdf. Acesso em: 28 mar. 2019.

AZEVEDO-RAMOS, C.; SILVA, J. N. M.; MERRY, F. The evolution of Brazilian forest concessions. Elementa: Science of the Anthropocene, v. 3, n. 48, p. 1-8, 2015.

BRASIL. Lei n. 4.771, de 15 de setembro de 1965. Institui o Código Florestal. Diário Oficial da União, Brasília, DF, 19 set. 1965. Disponível em: http://www.planalto. gov.br/ccivil_03/Leis/14771. htm. Acesso em: 15 ago. 2014.

BRASIL. Constituição da República Federativa do Brasil de 1988. Diário Oficial da União, Brasília, DF, 05 out. 1988. Disponível em: http://www.planalto.gov.br/ccivil_03/Constituicao/ Constituicao.htm. Acesso em: 12 jan. 2016.

BRASIL. Lei n. 9.985, de 18 de julho de 2000. Institui o Sistema Nacional de Unidades de Conservação da Natureza e dá outras providências. Diário Oficial da União, Brasília, DF, 19 jul. 2000. Disponível em: http://www.planalto.gov.br/ccivil_03/leis/L9985.htm. Acesso em: 20 fev. 2016.

BRASIL. Lei n. 11.284, de 02 de março de 2006. Dispõe sobre a gestão de florestas públicas para a produção sustentável. Diário Oficial da União, Brasília, DF, 03 mar. 2006. Disponível em: http:// www.planalto.gov.br/ccivil_03/_ato2004-2006/2006/lei/l11284.htm. Acesso em: 17 ago. 2015.

BRASIL. Lei n. 12.651, de 25 de maio de 2012. Dispõe sobre a proteção da vegetação nativa. Diário Oficial da União, Brasília, DF, 28 maio, 2012. Disponível em: http://www.planalto.gov. br/ ccivil_03/_ato2011-2014/2012/lei/112651.htm. Acesso em: 17 ago. 2015.

BRASIL. Ministério do Meio Ambiente. Cadastro Nacional de Unidades de Conservação. Tabela consolidada das unidades de conservação. Brasília, [2019]. Disponível em: https://www.mma. gov.br/images/arquivo/80229/CNUC_JUL19\%20-\%20B_Cat.pdf. Acesso em: 23 set. 2019.

BRASIL. Ministério do Meio Ambiente. Pilares para a sustentabilidade financeira do sistema nacional de unidades de conservação. Brasília: Ministério do Meio Ambiente, Secretaria de Biodiversidade e Florestas, Departamento de Áreas Protegidas. 2009a. 72 p.

BRASIL. Ministério do Meio Ambiente. Resolução n. 416, de 30 de setembro de 2009. Dispõe sobre a prevenção à degradação ambiental e dá outras providências. Diário Oficial da União, Brasília, DF, 01 mar. 2009b. Disponível em: http://www.mma.gov.br/port/conama/legiabre. cfm?codlegi=616. Acesso em: 28 jun. 2015.

CARNEIRO, M. S.; AMARAL NETO, M.; CASTRO, E. M. R. Sociedade, floresta e sustentabilidade. Belém: Instituto Internacional de Educação do Brasil; NAEA, 2013. 133 p.

CARVALHO, J. O. P. de et al. Manejo de florestas naturais do trópico úmido com referência especial à Floresta Nacional do Tapajós no Estado do Pará. Belém: EMBRAPA; CPATU, 184. 14 p. (Documento, 26).

CENTRO DE ESTUDOS EM SUSTENTABILIDADE. Contribuições para a análise de viabilidade econômica das propostas referentes à decuplicação da área de manejo florestal sustentável. São Paulo: Escola de Administração de Empresas de São Paulo da Fundação Getúlio Vargas, 2016. 65 p.

DRIGO, I. G. As barreiras para a implantação de concessões florestal na América do Sul: os casos de Bolívia e Brasil. 2010. Tese (Doutorado) - Universidade de São Paulo, São Paulo, 2010. 
FERNANDES, A. P. D. et al. Destination of public forests in Brazil: an analysis of forest concessions. Nativa, Sinop, v. 5, nesp., p. 497-503, 2017.

GODOY, M. G. A gestão sustentável e a concessão das florestas públicas. Revista Economia Contemporânea, Rio de Janeiro, v. 10, n. 3, p. 631-654, 2006.

HIGUCHI, N. et al. O mercado internacional de madeira tropical está à beira do colapso. SBPN Scientific Journal, São Paulo, v. 1, n. 2, p. 33-41, 2006.

HIGUCHI, N. et al. Perspectivas do manejo florestal sustentável para a Amazônia brasileira. Hiléia - Revista do Direito Ambiental da Amazônia, Manaus, n. 8, 2010.

INSTITUTO FLORESTA TROPICAL. As concessões de florestas públicas na Amazônia brasileira. Belém, 2014. 28 p.

JUVENAL, T. L.; MATTOS, R. L. G. O setor florestal no Brasil e a importância do reflorestamento. Rio de Janeiro: BNDES, 2002. (BNDES Setorial, n. 16).

KARSENTY, A. et al. Regulating industrial forest concessions in Central Africa and South America. Forest Ecology and Management, [s. l.], v. 256, p. 1498-1508, 2008.

LIMA, L. S. et al. Illegal logging as a disincentive to the establishment of a sustainable forest sector in the Amazon. PLOS ONE, San Francisco, p. 1-21, 2018.

MEDEIROS, R.; ARAÚJO, F. F. S. Dez anos do Sistema Nacional de Unidades de Conservação da Natureza: lições do passado, realizações presentes e perspectivas para o futuro. Brasília: Ministério do Meio Ambiente, 2011. 220 p.

MUNIZ, T. F.; PINHEIRO, A. S. O. Concessão florestal como instrumento para a redução de exploração ilegal madeireira em Unidades de Conservação em Rondônia. Revista FAROL, Rolim de Moura, v. 8, n. 8, p. 121-142, 2019.

NOGUEIRA, J. M.; RODRIGUES, A. A. Manual de Valoração Econômica de Florestas Nacionais. Quarto relatório, versão corrigida, do Estudo sobre Valoração Econômica de Florestas Nacional: Produtos Madeireiros e Não Madeireiros do Projeto PNUD/BRA 97/044 - Desenvolvimento Florestal Sustentável. Brasília: IBAMA; FUNTEC, 2007. p. 385-393.

PEREIRA, D. et al. Fatos florestais da Amazônia 2010. Belém: Imazon, 2010. 126 p.

RUSCHEL, A. R. Dinâmica da composição florística e do crescimento de uma floresta explorada há 18 anos na Flona Tapajós, PA. Belém: EMBRAPA Amazônia Oriental, 2008. 57 p. (Documentos, 341).

SABOGAL, C. et al. Manejo empresarial da Amazônia brasileira. Belém: CIFOR, 2006. 74 p.

SANTOS, A. A. B. Conselhos gestores de unidades de conservação. 2008. Tese (Doutorado) Universidade de Brasília, Brasília, 2008.

SERVIÇO FLORESTAL BRASILEIRO. Plano anual de outorga florestal 2020. Brasília, [2019]. 81 p. Disponível em: http://www.florestal.gov.br/publicacoes/1690-plano-anual-de-outorgaflorestal-paof-2020. Acesso em: 25 set. 2019.

SILVA, K. E. et al. Concessões de florestas públicas na Amazônia: desafios para o uso sustentável dos recursos florestais. Bioikos, Campinas, v. 23, n. 2, p. 91-102, 2009.

SILVA, L. F.; SILVA, M. L. CORDEIRO, S. A. Análise do mercado mundial de madeiras tropicais. Revista de Política Agrícola, Brasília, v. 21, n. 3, p. 48-54, 2012.

VILANOVA, E. et al. Compliance with sustainable forest management guidelines in three timber concessions in the Venezuelan Guayana: Analysis and implications. Forest Policy and Economics, [s. l.], v. 17, p. 3-12, 2012. 